\title{
Cloning and Expression of Outer Membrane Protein Omp38 Derived from Aeromonas hydrophila in Escherichia coli
}

\author{
Le Thi Kim Phuong ${ }^{1}$, Nguyen Hieu Nghia ${ }^{2}$, Thi Hoa Rol ${ }^{3}$, Nguyen Thi My Trinh ${ }^{4}$, Dang Thi Phuong Thao ${ }^{5 *}$ \\ ${ }^{1}$ PhD Scholar, Laboratory of Molecular Biotechnology, VNUHCM-University of Science, Vietnam \\ ${ }^{2}$ Student, Laboratory of Molecular Biotechnology, VNUHCM-University of Science, Vietnam \\ ${ }^{3}$ Student, Laboratory of Molecular Biotechnology, VNUHCM-University of Science, Vietnam \\ ${ }^{4}$ Postdoctoral Researcher, Laboratory of Molecular Biotechnology, VNUHCM-University of Science, Vietnam \\ ${ }^{5}$ Associate Professor, Laboratory of Molecular Biotechnology, VNUHCM-University of Science, Vietnam
}

*Address for Correspondence: Dr. Dang Thi Phuong Thao, Laboratory of Molecular Biotechnology, University of Science, Vietnam National University- Ho Chi Minh City, Ho Chi Minh city, Vietnam

E-mail: dtpthao@hcmus.edu.vn

Received: 27 Oct 2018/ Revised: 28 Mar 2019/ Accepted: 30 Apr 2019

\begin{abstract}
Background: Aromonas hydrophila is an aquatic bacterium involved in various diseases in fish, resulting in serious economic losses every year. In previous studies, the outer membrane protein Omp38 was demonstrated to have high immunoprotection capacity, suggesting the use of this protein as a vaccine candidate to protect fish against $A$. hydrophila in fish aquacultures.

Methods: The gene coding for Omp38 was amplified from A. hydrophila genome and inserted into BamHI/Xhol sites of plasmid pET-28a(+). The recombinant plasmid was then introduced into $E$. coli BL21(DE3). Transformed $E$. coli cells were treated with IPTG to induce the expression of Omp38 fused with $6 \mathrm{xHis}$ tag. The presence of $6 \mathrm{xHis-Omp38}$ was detected by western blot analysis using an anti-Histidine antibody.

Results: We successfully constructed an E. coli strain that can highly express Omp38 protein (comprising $40 \%$ of total cell proteins). The Omp38 protein was expressed as the form of inclusion bodies so that it could be easily obtained from cell lysate with high purity ( $\geq 95 \%)$ by centrifugation.

Conclusion: This study was the first step in an attempt to produced Omp38-based vaccine to prevent the outbreak of diseases caused by $A$. hydrophila in fish farming.
\end{abstract}

Key-words: Aeromonas hydrophila, Escherichia coli, Omp38, Outer membrane protein, Recombinant protein

\section{INTRODUCTION}

A.hydrophila is a facultative anaerobic, Gram-negative, and rod-shape bacterium that can live in a wide range of temperatures, pHs, conductivities and turbidities, but favorably grows in warm climates ${ }^{[1,2]}$. A. hydrophila is considered as an opportunistic pathogen responsible for numerous diseases in human such as gastroenteritis, skin infections, peritonitis, bacteremia, hemolytic uremic syndrome, and necrotizing fasciitis, etc ${ }^{[3,4]}$. Especially,

\footnotetext{
How to cite this article

Phuong LTK, Nghia NH, Rol TH, Trinh NTM, Thao DTP. Cloning and Expression of Outer Membrane Protein Omp38 Derived from Aeromonas hydrophila in Escherichia coli. SSR Inst. Int. J. Life Sci., 2019; 5(3): 2328-2334.
}

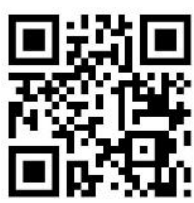

this bacterium is also a well-established fish pathogen that causes hemorrhagic septicemia and red sore disease in carp, catfish, salmone, dogfish, and goby, that results in huge global economic losses every year ${ }^{[1,5]}$. In China, outbreaks of motile Aeromonas septicemia were responsible for losses of 2,200 tons of dead fish per year [6]. In the summer of 2009, an outbreak of the same disease resulted in an estimated loss of more than 12 million dollars in catfish farming in the southeastern United States ${ }^{[7]}$.

To prevent the infection of $A$. hydrophila, commercial antibiotics are traditionally and popularly used in fish farming ${ }^{[8]}$. However, the overuse of antibiotics has raised concerns regarding the development of antibiotic resistance that seriously affects public health ${ }^{[9,10]}$. Therefore, in previous studies, some vaccines, including heat-killed bacteria ${ }^{[11]}$, S-layer recombinant protein ${ }^{[12]}$, 
lipopolysaccharide [13], attenuated bacteria [14], and biofilm oral vaccine ${ }^{[15]}$ were developed to control the spread of $A$. hydrophila and also to reduce the use of antibiotics. Recently, the bacterial outer membrane proteins (Omps) have been gained attention as potential vaccines due to their high immunoprotective capacities [16,17]. Importantly, among various Omps in A. hydrophila, the vaccination with Omp38 can effectively protect fish against this bacterium through the stimulation of both specific and non-specific immune responses as demonstrated by Wang et al. ${ }^{[18]}$.

For the reasons mentioned above, in this study, we focused on establishing an $E$. coli strain that can express A. hydrophila Omp38 for the future application in vaccine production. The recombinant Omp38 can also be used to produce a specific antibody, which has not yet been available on market.

\section{MATERIALS AND METHODS}

Bacterial strains, Medium and Other Reagents- The $E$. coli strains DH5 $\alpha$ ( $F^{-}$Ф80lacZ $\Delta$ M15 $\Delta$ (lacZYA-argF)U169 recA1 endA1 hsdR17 $\left(r_{K}{ }^{-}, m_{K}{ }^{+}\right)$phoA supE44 $\lambda^{-}$thi1 gyrA96 relA1) and BL21(DE3) ( $\mathrm{F}^{-}$ompT hsdS $\mathrm{S}_{B}\left(\mathrm{r}_{\mathrm{B}}{ }^{-}\right.$, $\mathrm{m}^{-}{ }^{-}$) gal dcm (DE3) (Thermo Fisher Scientific, USA) were used for the cloning and expression of recombinant Omp38. The A. hydrophila strain used in the current study for omp38 gene amplification was isolated from diseased fish in aquaculture of the Mekong Delta, Vietnam. All bacterial strains were cultured at $37^{\circ} \mathrm{C}$ in LB broth ( $1 \%$ trypton, $0.5 \%$ yeast extract, and $0.5 \% \mathrm{NaCl}$ ) with reciprocal shaking $(250 \mathrm{rpm})$. All enzymes for DNA cloning were purchased from Invitrogen (USA). The DNA ladder HyperLadder ${ }^{\mathrm{TM}} 1 \mathrm{~kb}$ and the Peptide Molecular Weight Marker were purchased from Bioline (USA) and GE Healthcare (USA), respectively. The other chemicals and reagents were obtained from Merck (USA).

Plasmid construction- The coding sequence of Omp38 (1008 bp) was amplified from A. hydrophila genome using primer pair omp38-F (5'-GGA AGA TCT GGATCC GTC ATC TAT CAG GCC GAT GAC GGC TCC AAC GTC G-3') and omp38-R (5'-CCG CTC GAG CGG ATG GTG ATG GTG ATG GTG GAA CTC GTA GCG CAG GCC GAG GTG GTA-3'). The plasmid pET-28a(+) (Novagen, USA) was isolated from DH5 $\alpha /$ pET-28a(+) using EZ-10 Spin Column Plasmid DNA Miniprep Kit (Bio Basic Inc., Canada). The PCR product was cloned into BamHI/Xhol sites of plasmid
pET-28a(+) and in-frame with polyhistidine tag (6xHis) sequence to construct pET-omp38 ${ }^{[19]}$. The ligation mixture was then transformed into $\mathrm{DH} 5 \alpha$ cells and the transformed clones were screened on $100 \mu \mathrm{g} / \mathrm{ml}$ ampicillin containing agar plates ${ }^{[20]}$. The recombinant plasmids containing omp38 gene were selected using PCR and further verified by Sanger sequencing.

Expression of recombinant Omp38- The plasmid pETomp38 was transformed into BL21(DE3) cells to establish the strain $B L 21(D E 3) / p E T-o m p 38$ that can express the recombinant protein fused with $6 x \mathrm{His}$ tag $(6 \mathrm{xHis}-$ Omp38). A colony of transformed cells was cultured in $100 \mathrm{ml} \mathrm{LB}$ medium containing $100 \mu \mathrm{g} / \mathrm{ml}$ ampicillin at $37^{\circ} \mathrm{C}$ with shaking (250 rpm) in an Erlenmeyer flask (300 $\mathrm{ml}$ ). When the culture reached $\mathrm{OD} \sim 0.8,1 \mathrm{mM}$ isopropyl $\beta$-D-1-thiogalactopyranoside (IPTG) was added to induce the expression of $6 x \mathrm{His}-\mathrm{Omp} 38$. Cells were further cultured for 4 hours and then $1 \mathrm{ml}$ of the culture was centrifuged at $6,000 \mathrm{~g}$ for 10 minutes to harvest cells. Cells were washing and re-suspended in $1 \mathrm{ml}$ of $0.1 \mathrm{mM}$ phosphate buffer $\mathrm{pH}$ 7. After that, cells were disrupted by sonication and $500 \mu$ of cell lysate was centrifuged at $10,000 \mathrm{~g}$ for 5 minutes to separate the supernatant and pellet fractions. The pellet fraction was then suspended into $500 \mu \mathrm{l}$ of $0.1 \mathrm{mM}$ phosphate buffer $\mathrm{pH}$ 7. Fifty microlitter of total cell lysate, supernatant and pellet fractions were mixed with $10 \mu \mathrm{l}$ sample buffer $6 \mathrm{X}(0.35$ $\mathrm{M}$ Tris- $\mathrm{HCl}, 10 \%$ SDS, 36\% glycerol, $0.6 \mathrm{M}$ dithiothreitol, $0.012 \%$ bromophenol blue, $\mathrm{pH} 6.8$ ) and heated at $100^{\circ} \mathrm{C}$ for 10 minutes for protein denaturation. After that, $10 \mu \mathrm{l}$ of each sample was applied to each lane of a polyacrylamide gel (12.5\%) for SDS-PAGE analysis ${ }^{[21]}$. An His-probe antibody (H-3): sc-8036 (Santa Cruz Biotechnology Inc., USA) was used to detect 6xHisOmp38. We used Anti-mouse IgG (whole molecule)Peroxidase antibody (A-9044, Sigma-Aldrich, USA) as the second antibody, and the signal was detected by $\mathrm{ECL}^{\mathrm{TM}}$ Prime Western Blotting Detection Reagent (GE Healthcare Amersham ${ }^{\mathrm{TM}}$, UK). The purity of Omp38 protein in pellet fraction was determined using ImageJ software ${ }^{[22]}$. 


\section{RESULTS}

Amplification of omp38 gene and construction of plasmid pET-omp38- For the high expression of Omp38 protein, $\mathrm{pET}-28 \mathrm{a}(+)$ was chosen as a vector to carry the target gene into $E$. coli cells. The omp38 gene was inserted into BamHI/Xhol site of pET-28a(+) so that this gene can be effectively expressed under the control of the very strong $T 7$ promoter.

With the purpose mentioned above, the omp38 gene was amplified from $A$. hydrophila by PCR, with a BamHI and an Xhol at the 5'- and 3'-end, respectively. Electrophoresis of PCR products showed that the length

\section{(A)}

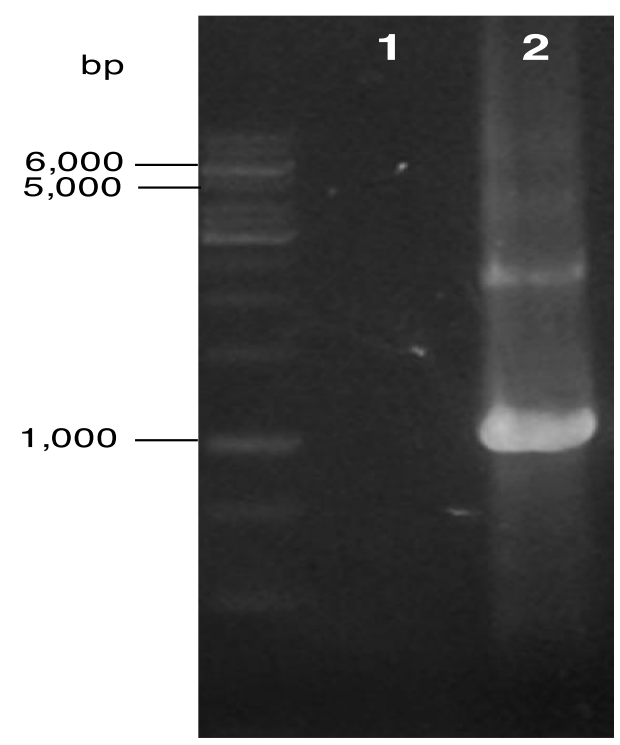

of amplicons was approximately $1,000 \mathrm{bp}$ that was in accordance with the theoretical length of omp38 gene (Fig. 1A). The PCR products were then digested with restriction enzymes $\mathrm{BamHI}$ and Xhol, yielding a DNA fragment with two sticky-ends for DNA cloning.

The plasmid pET-28a(+) was also digested with the same restriction enzymes, that generated a single DNA band between 5,000 and 6,000 bp in size (Fig. 1B). After digested, PCR products and plasmids were ligated using T4 DNA ligase and the ligation mixture was then transformed into $\mathrm{DH} 5 \alpha$ cells to select recombinant plasmids.

\section{(B)}

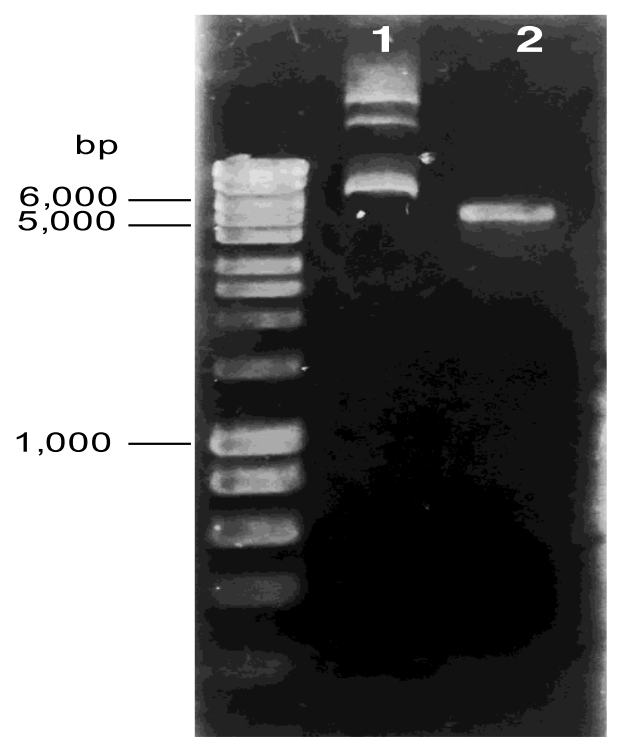

Fig. 1: Gene and plasmid preparation

(A) ORF sequence of omp38 gene was amplified from A. hydrophila genome by PCR. Samples were as follows: 1- No template control; 2- PCR products

(B) Plasmid pET-28a(+)

Samples were as follows: 1- Purified plasmid; 2- Plasmid digested with BamHI/ Xhol

The transformed cells were then spread on an LB agar plate containing $100 \mathrm{\mu g} / \mathrm{ml}$ ampicillin. Ten colonies grown on this plate were randomly chosen and subjected to colony-PCR with primers omp38-F/R (Fig. 2A). The electrophoresis result showed that DNA bands representing omp38 gene were present in 6/10 samples, suggesting that these colonies were successfully transformed with pET-omp38.

We next isolated plasmids from the above six omp38positive clones and used them as templates for PCR analysis with omp38-F primer and the T7-terminator primer (5'-GCT AGT TAT TGC TCA GCG G-3') to verify the insertion of omp38 gene into plasmid pET-28a(+). We found that all reactions from these six plasmids produced a DNA band around 1,100 bp (Fig. 2B), that was equal to the size of omp38 ORF plus the length from Xhol position to the T7-terminator primer binding site. This result indicated that all these plasmids contained omp38 gene with proper direction. 


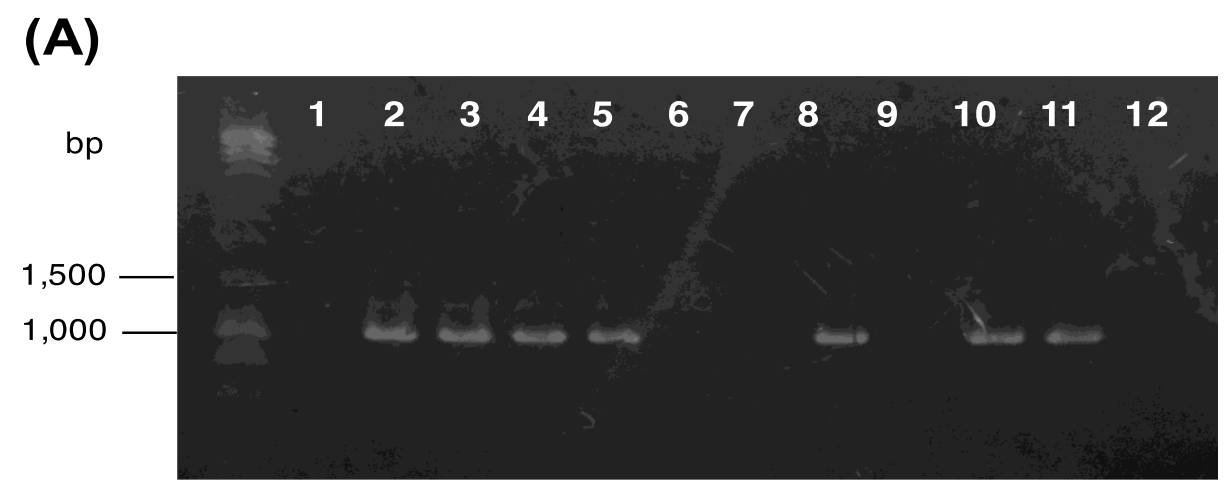

(B)

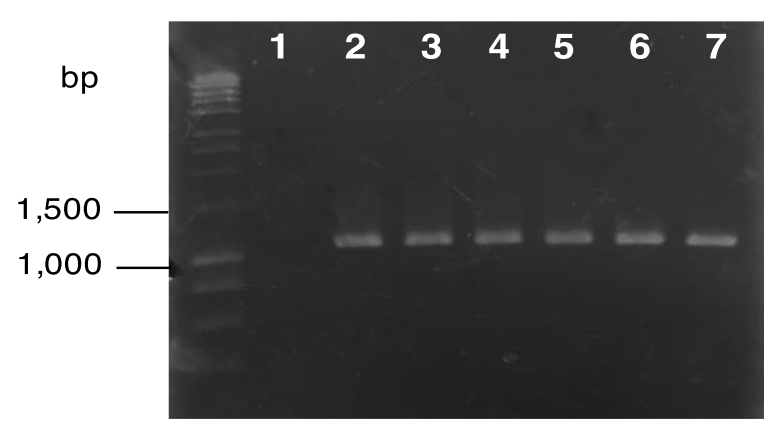

Fig. 2: Selection of recombinant plasmids

(A) Obtained colonies were analyzed by PCR with primers omp38-F/R to select the omp38-positive colonies. Samples were as follows: 1- No template control; 2- PCR product from A. hydrophila genome (positive control), 3 to 12- PCR products from ten randomly chosen colonies

(B) Candidate plasmids were verified by PCR with omp38-F and T7 terminator primers. Samples were as follows: 1- No template control; 2 to 7- PCR products from six plasmids

DNA sequencing and Database search- The cloned omp38 gene was sequenced using the Sanger method and the result (Fig. 3) was submitted to a BLAST server (http://www.ncbi.nlm.nih.gov/BLAST/) to check the sequence accuracy. The interpreting BLAST output showed that there are some variety of Omp38 proteins among $A$. hydrophila strains and the omp38 sequence obtained in this study was the same as those found in nine $A$. hydrophila strains i.e. ZYAH72, GYK1, D4, JBN2301, NJ-35, J-1, pc104A, AL09-71, and ML09-119 with $100 \%$ identity with $100 \%$ coverage. These data demonstrated that we successfully and correctly inserted omp38 gene into pET-28a(+).

Expression of Omp38 protein- The plasmid pET-omp38 was transformed into BL21 (DE3) cells to produce Omp38. The BL21 (DE3) strain carries the gene coding for T7 RNA polymerase under the control of lacUV5 promoter. The adding of IPTG induces the expression of T7 RNA polymerase and subsequently stimulates the expression of omp38 gene downstream of the T7 promoter in $\mathrm{pET}$-omp38 plasmid.

Therefore, a colony of transformed cells was cultured in LB medium containing $100 \mu \mathrm{g} / \mathrm{ml}$ ampicillin and $1 \mathrm{mM}$ IPTG was added to induce the expression of recombinant protein. Cells were disrupted and then soluble proteins and aggregates were separated and analyzed by SDSPAGE method. Lysates of BL21(DE3) cells and BL21(DE3)/pET-omp38 cells untreated with IPTG were used as the negative controls. A clear protein band around $38 \mathrm{kDa}$ appeared in induced BL21(DE3)/pETomp38 sample and was absent in all negative controls (Fig. 4A). Since omp38 protein is fused with $6 \mathrm{xHis}$ tag, this band could be detected by western blot analysis with anti-Histidine antibody (Fig. 4B). These results indicated that the addition of IPTG induced the expression of $6 x$ His-Omp38 protein and that we successfully established an $E$. coli strain that can produce Omp38 protein. 
1 GTC ATC TAT CAG GCC GAT GAC GGC TCC AAC GTC GAT CTC TAC GGT CGC CTC GGC TTC AAC

61 ATC TCG GAC AAG AAG AGC GGC AAC GAT CAG GGC GAC TTC GAC GGT CGC ATC GGC TTC ACC 121 GCC CGC CAG ACC GTC AAC GAG CAG GTA GCC GTG ATC GGC ATG GCT CAG TAC CAG GTC AAC 181 GCC GCC GAA TAC GCC AAC AAC GTG CAG AAG AAC AGC AGC GAT CTC ACC GCC CGT TAC GTC 241 TGG GCC GGG CTC GAT GGC GGC CAG TGG GGC AAG CTG ACC GGT GGC CGG GTC TCC TCC GGG 301 CTC ATC ATG TTC ACC GAC ATC GGC GAC GTG TIT GCC GCC TCC GAT GTC TCC ATG GCG CGC 361 CAG GCC AGC AAA GTG GAC TCC ACC GCG GTA CAG GTG TTC CGT CAG GAC GGC ACC CTG CAA 421 TAC CAG AAC ACC CTC GGC AAT CTG GAC TTG TCG CTG GCC TAC ATC CTC GGC AAC GGC ACC 481 TCG GAT CTC AAC TAC GGC TAC AAC GGC GCC CTG CGC TAC ACC TTC GAT CTC GGG GCG GCG 541 GGC AAG CTG GCG CCG GTC ATC GCC TAC CAG CAG AGC AAG GCG GCC CAG ACC GGT GCC AGC 601 AAA GTC GAC CCC AAT GCC GAC GAG TAC CGC TTC AGC GGC ATC GGC ACC CGC TAC ACC CTG 661 GGA CCG CTG ATG CTG GGC GCC CTC TAT GCC AAG GAT CAG GTG AGC TAT CGC AAC GGC CAA 721 GCG GAC AGC GAA GAC AAG GTG TGG GAG CTG ACC GCC GTC TAC GAC ATC CAC CAG AAG TGG 781 GCC GCC CGC GCC GGC TAC CGC CAC CTC GAC AAC GAC GGG GGA GAC GGC ATG AGC CTG CGC 841 GAC ACT ACC CTG GAG CTG CAG TAC AAG CTC ACT CCG CGC TCC TCC CTC TAT AGC GCC TAC 901 GTG TTC CGG GGC GGT GAA GAC GGG CTG GCC GGC AGC ACG GTC ACC AGT TTT GGC GGC AGC AGC AAC AGC GAG GAT TTC TAC CAC CTC GGC CTG CGC TAC GAG TTC TGA

Fig. 3: DNA sequence of the omp38 gene that was cloned in this study

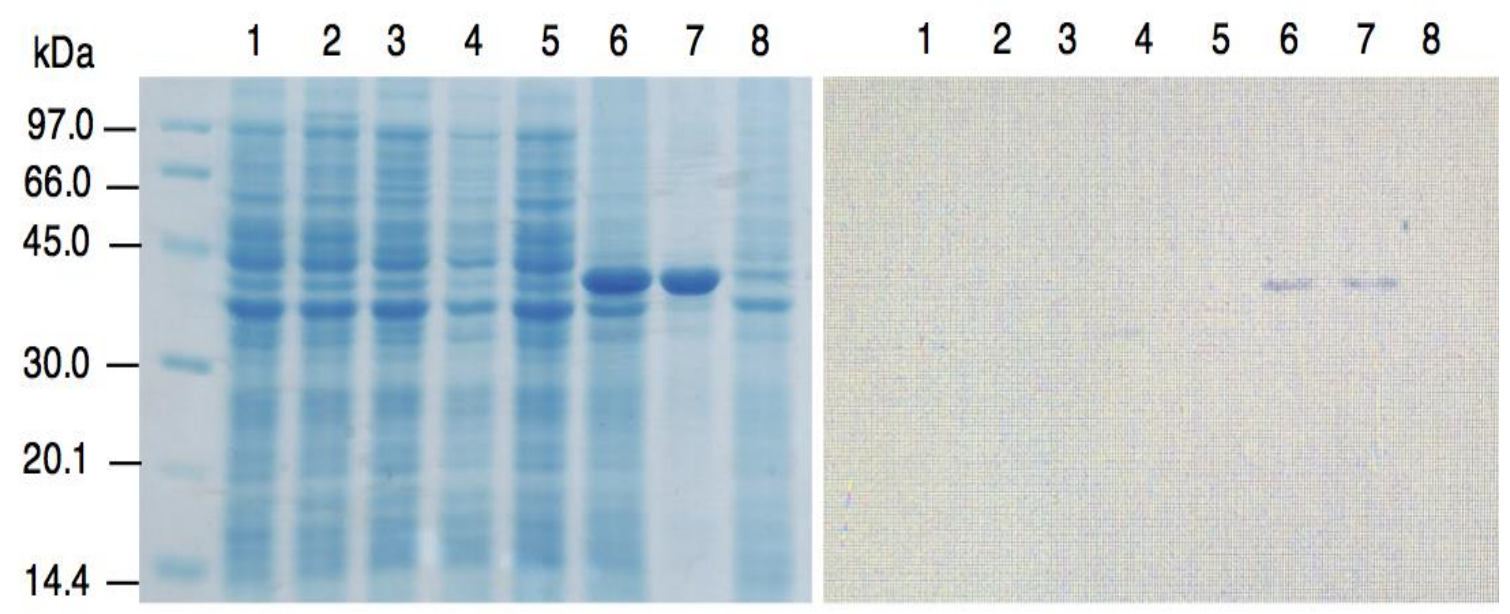

Fig. 4: The expression of $6 x$ His-Omp38 protein was analyzed by SDS-PAGE (A) Western Blot analysis (B) Samples were as follows: 1- Un-induced BL21(DE3); 2- IPTG-induced BL21(DE3); 3- Un-induced BL21(DE3)/pET28a(+); 4- IPTG-induced BL21(DE3)/pET-28a(+); 5- Un-induced BL21(DE3)/pET-omp38; 6- IPTG-induced BL21(DE3)/pETomp38, total proteins; 7- IPTG-induced BL21(DE3)/pET-omp38, insoluble fraction, 8- IPTG-induced BL21(DE3)/pETomp38, soluble fraction

Additionally, we also found that this protein was mostly expressed in inclusion body form since it was not observed in the soluble fraction of cell lysate (Fig. 4A). The formation of such aggregates is considered to be a benefit for protein purification, as almost bacterial native proteins are soluble. Accordingly, the ImageJ analysis of SDS-PAGE picture (Fig. 4A) showed that the Omp38 protein comprised approximately $40 \%$ of total proteins in cell lysate (well 6) and was present in insoluble fraction with high purity ( 95\%) (well 7).

\section{DISCUSSION}

As stated in pET system manual (Novagen, USA), the pET plasmid system is a very powerful tool for recombinant protein expression, which allowed the high expression level of target protein, up to $50 \%$ of the total cell protein amount ${ }^{[19]}$. Therefore, in this study, we chose pET-28a(+) plasmid for the expression of our target protein Omp38 and succeeded in creating the $E$. coli strain BL21(DE3) expressing $6 \mathrm{xHis}$ tag-fused Omp38 protein, which represented $\sim 40 \%$ of total cell proteins (Fig. $4 A$ ). This result was achieved under the current unoptimized 
conditions in a $100 \mathrm{ml}$-flask scale and might be improved by the further optimization and tighter control of the medium, $\mathrm{pH}$, oxygen concentration, and other culture conditions using a fermenter.

In two previous studies, in order to evaluate the Omp38 protein as a vaccine antigen against $A$. hydrophila, Wang et al. ${ }^{[18]}$; $\mathrm{Ni}$ et al. ${ }^{[23]}$ also used the same system for Omp38 expression, and after purification using HisTrap ${ }^{\mathrm{TM}}$ $\mathrm{HP}$, the protein purities obtained were about $80 \%$ and $90 \%$, respectively. We here found that the target protein 6xHis-Omp38 was expressed mostly in inclusion body form and comprised about $95 \%$ of the aggregated protein in E. coli cells (Fig. 4A, well 7). Therefore, compared to the above studies, our target 6 xHis-Omp38 protein can be easily obtained with higher purity using a centrifuge. However, if a very high purity is required (>95\%), the recombinant Omp38 can be simply purified using Ni-NTA affinity chromatography ${ }^{[24]}$.

Additionally, Kasik et al. ${ }^{[25]}$ found that inclusion bodies carrying the E2 antigen of classical swine fever virus induced both systemic and mucosal responses when being fed to mice without any adjuvant. Therefore, it seems that the obtained Omp38 inclusion bodies can be directly used as an oral vaccine without any further step. On the other hand, according to $\mathrm{Ni}$ et al. ${ }^{[23]}$ the omp38 gene could be detected in $75 \%$ of the tested $A$. hydrophila strains, suggesting that although Omp38 protein showed high immunoprotective activity, the vaccination with Omp38 protein could protect fish against most, but not all, A. hydrophila strains. Therefore, an approach based on the combination of Omp38 and some other outer membrane proteins should be considered to widen the range of protected strains.

\section{CONCLUSIONS}

In this study, we successfully established an E. coli strain that could highly express Omp38 protein (making up $\sim 40 \%$ of total proteins) when being induced by IPTG. The Omp38 protein was expressed as inclusion bodies so that it could be easily obtained with high purity ( $95 \%)$ from cell lysate by centrifugation.

The inclusion body obtained in this study can be directly used as a potential vaccine candidate for fish to control the spread of $A$. hydrophila or to produce a specific antibody by immunization of animals. Since inclusion bodies are relatively stable, the mixing of Omp38 aggregates and food for oral administration might be an effective approach for labor-effective fish vaccination. Additionally, the simple process to obtain high-purity Omp38, as shown in this study, might also enable us to produce a cost-effective vaccine that can replace antibiotics in fish farming.

\section{ACKNOWLEDGMENTS}

This study was supported by a fund from the University of Science, Vietnam National University-Ho Chi Minh city, Vietnam.

\section{CONTRIBUTION OF AUTHORS}

Research design: Dang Thi Phuong Thao

Data collection: Le Thi Kim Phuong, Thi Hoa Rol, Nguyen Hieu Nghia

Data analysis and Interpretation: Le Thi Kim Phuong, Nguyen Thi My Trinh, Dang Thi Phuong Thao

Literature search: Le Thi Kim Phuong, Nguyen Thi My Trinh

Writing article: Nguyen Thi My Trinh

Critical review: Nguyen Thi My Trinh, Dang Thi Phuong

Thao

Article editing: Nguyen Thi My Trinh

Final approval: Dang Thi Phuong Thao

\section{REFERENCES}

[1] Janda JM, Abbott SL, The genus Aeromonas: taxonomy, pathogenicity, and infection. Clin. Microbiol. Rev., 2010; 23(1): 35-73.

[2] Hochedez P, Hope-Rapp E, Olive C, Nicolas M, Beaucaire $G$, et al. Bacteremia caused by Aeromonas hydrophila complex in the Caribbean Islands of Martinique and Guadeloupe. Am. J. Trop. MedMed. Hyg., 2010; 83(5): 1123-27.

[3] Igbinosa IH, Igumbor EU, Aghdasi F, Tom M, Okoh Al. Emerging Aeromonas species infections and their significance in public health. Sci. World J., 2012; 2012: 625023.

[4] Liakopoulos V, Arampatzis S, Kourti P, Tsolkas T, Zarogiannis S, et al. Aeromonas hydrophila as a causative organism in peritoneal dialysis-related peritonitis: case report and review of the literature. Clin. Nephrol., 2011; 75(1): 65-68.

[5] AlYahya SA, Ameen F, Al-Niaeem KS, Al-Sa'adi BA, Hadi $S$, et al. Histopathological studies of experimental Aeromonas hydrophila infection in blue tilapia, Oreochromis aureus. Saudi J. Biol. Sci., 2018; 25(1): 182-85. 
[6] Rasmussen-Ivey CR, Hossain MJ, Odom SE, Terhune JS, Hemstreet WG, et al. Classification of a hypervirulent Aeromonas hydrophila pathotype responsible for epidemic outbreaks in warm-water fishes. Front .Microbiol., 2016; 7: 1615.

[7] Hossain MJ, Sun D, McGarey DJ, Wrenn S, Alexander LM, et al. An Asian origin of virulent Aeromonas hydrophila responsible for disease epidemics in United States-farmed catfish, 2014; 5(3): 01-07.

[8] Stratev D, Odeyemi OA. Antimicrobial resistance of Aeromonas hydrophila isolated from different food sources: A mini-review. J. Infect. Public Health, 2016; 9(5): 535-44.

[9] Shallcross L, Davies DSC. Antibiotic overuse: A key driver of antimicrobial resistance. Br. J. Gen. Pract., 2014; 64(629): 604-05.

[10]Ventola CL. The antibiotic resistance crisis: part 1: causes and threats. Pharm. Ther., 2015; 40: 277-83.

[11]Vasudeva RY, Das BK, Jyotyrmayee P, Chakrabarti R. Effect of Achyranthes aspera on the immunity and survival of Labeo rohita infected with Aeromonas hydrophila. Fish Shellfish Immunol., 2006; 20(3): 263-73.

[12]Poobalane S, Thompson KD, Ardo L, Verjan N, Han $\mathrm{HJ}$, et al. Production and efficacy of an Aeromonas hydrophila recombinant S-layer protein vaccine for fish. Vaccine, 2010; 28(20): 3540-47.

[13]Dehghani S, Akhlaghi M, Dehghani M. Efficacy of formalin-killed, heat-killed and lipopolysaccharide vaccines against motile Aeromonads infection in rainbow trout (Oncorhynchus mykiss). Glob. Vet., 2012; 9: 409-15.

[14]Pridgeon JW, Yildirim-Aksoy M, Klesius PH, Srivastava $\mathrm{K}$, Reddy PG. Attenuation of a virulent Aeromonas hydrophila with novobiocin and pathogenic characterization of the novobiocin-resistant strain. J. Appl. Microbiol., 2012; 113(6): 1319-28.

[15]Siriyappagouder P, Shankar KM, Naveen Kumar BT, Patil R, et al. Evaluation of biofilm of Aeromonas hydrophila for oral vaccination of Channa striatus. Fish Shellfish Immunol., 2014; 41(2): 581-85.
[16]Pan J, Li C, Ye Z. Immunoproteomic approach for screening vaccine candidates from bacterial outer membrane proteins. Methods Mol. Biol., 2016; 1404: 519-28.

[17]Poolman JT. Bacterial outer membrane protein vaccines. The meningococcal example. Adv. Exp. Med. Biol., 1996; 397: 73-77.

[18]Wang N, Yang Z, Zang M, Liu Y, Lu C. Identification of Omp38 by immunoproteomic analysis and evaluation as a potential vaccine antigen against Aeromonas hydrophila in Chinese breams. Fish Shellfish Immunol., 2013; 34(1): 74-81.

[19] Novagen. pET system manual. $10^{\text {th }}$ ed., 2003.

[20]Froger A, Hall JE. Transformation of Plasmid DNA into E. coli Using the Heat Shock Method. J. Vis. Exp., 2007; 6(523).

[21]Brunelle JL, Green J. One-dimensional SDSpolyacrylamide gel electrophoresis (1D SDS-PAGE). Methods Enzymol., 2014; 541: 151-59.

[22] Schneider CA, Rasband WS, Eliceiri KW. NIH Image to Image J: 25 years of image analysis. Nature Med., 2012; 9(7): 671-75.

[23]Ni XD, Wang N, Liu YJ, Lu CP. Immunoproteomics of extracellular proteins of the Aeromonas hydrophila China vaccine strain J-1 reveal a highly immunoreactive outer membrane protein. FEMS Immunol. Med. Microbiol., 2010; 58(3): 363-73.

[24]Bornhorst JA, Falke JJ. Purification of proteins using polyhistidine affinity tags. Methods Enzymol., 2000; 326: 245-54.

[25]Kesik M, Saczynska V, Szewczyk B, Płucienniczak A. Inclusion bodies from recombinant bacteria as a novel system for delivery of vaccine antigen by the oral route. Immunol. Lett., 2004; 91(2-3): 197-204. 